\title{
Effect of Trace Sm Addition on Microstructure and Mechanical Properties of AZ61 Magnesium Alloys
}

\author{
Hu Zhi ${ }^{1}, \quad$ Hua Qun ${ }^{1}, \quad$ Yan Hong ${ }^{1}, \quad$ Jie Xiaoping ${ }^{1}, \quad$ Rao Yuansheng ${ }^{1}$ \\ ${ }^{1}$ Nanchang University, Nanchang 330031, China; ${ }^{2}$ Key Laboratory of Light Alloy Preparation \& Processing in Nanchang City, Nanchang \\ 330029, China
}

\begin{abstract}
The effect of samarium (Sm) adding (0.0 wt $\%, 0.5 \mathrm{wt} \%, 1.0 \mathrm{wt} \%, 1.5 \mathrm{wt} \%$ and $2.0 \mathrm{wt} \%)$ on microstructure and mechanical properties of AZ61 magnesium alloys was investigated by OM, XRD, SEM and EDS. The results indicate that volume fraction $0.4 \% \sim 2.2 \% \mathrm{Al}_{2} \mathrm{Sm}$ particles with the average diameter of 1 7 $\mu \mathrm{m}$ are found in AZ61 magnesium alloys with different $\mathrm{Sm}$ contents addition. When Sm content increases from $0.0 \mathrm{wt} \%$ to $2.0 \mathrm{wt} \%$, the particle size of $\mathrm{Al}_{2} \mathrm{Sm}$ gradually increases while the content of $\beta-\mathrm{Mg}_{17} \mathrm{Al}_{12}$ decreases. Meanwhile the grain size of AZ61 magnesium alloys after solution treatment at $693 \mathrm{~K} \mathrm{for} 24 \mathrm{~h}$ firstly decreases and then increases with Sm content increasing. When Sm content is $1.0 \mathrm{wt} \%$, the grain size is least. The ultimate tensile strength, the yield stress and the elongation of AZ61 magnesium alloys with $1.0 \mathrm{wt} \% \mathrm{Sm}$ after solution treatment are 215, 142 $\mathrm{MPa}$, and $4.1 \%$, respectively, up to their maximum values.
\end{abstract}

Key words: rare earth; Sm; magnesium alloy; intermetallic compound; microstructure; mechanical properties

Magnesium alloys are important in the weight reduction of vehicles because of their low density and high strength-to-weight ratio. The use of magnesium and its alloys in the automotive industry has markedly increased in the past several years ${ }^{[1,2]}$. Currently, the most common magnesium alloys, such as AZ91 and AZ61, occupy 90\% of the total magnesium alloys used in the automotive industry ${ }^{[3,4]}$. Although the AZ61 magnesium alloy exhibits superior elongation to the AZ91 alloy, the former has a lower strength than the latter. Hence, enhancing mechanical properties of the AZ61 magnesium alloy is vital to satisfy the required property for automobile parts. Mechanical properties of magnesium alloys can be enhanced by the addition of minor alloying elements. Rare earth metals are important alloying elements to improve mechanical properties, casting characteristics, and high temperature properties of these alloys ${ }^{[5-7]}$.

Recently, Zhang et al ${ }^{[8]}$ reported that $\mathrm{Nd}$ addition refines microstructure of the AM60 magnesium alloy. Optimal properties of AM60 magnesium alloys are obtained when $0.9 \% \mathrm{Nd}$ is added as an alloying element. Liu et al ${ }^{[9]}$ found a new $\gamma$ phase containing high amounts of $\mathrm{Re}$ and $\mathrm{Al}$ elements in the AM60 magnesium alloy and the corrosion resistance of the alloys was improved with the addition of Ce and La. Huang et al ${ }^{[10]}$ reported that the $\alpha(\mathrm{Mg})$ phase morphology is gradually transformed from dendritic to the equiaxed crystal with the increasing Ce content. The size and amount of the $\mathrm{Mg}_{17} \mathrm{Al}_{12}$ phases are reduced as a result of $\mathrm{Al}_{11} \mathrm{Ce}_{3}$ formation. Tensile properties of die-cast AM60 alloys with $\mathrm{Ce}$ addition are remarkably improved because of the grain refinement.

The solid solubility of rare earth $\mathrm{Sm}$ in the $\alpha(\mathrm{Mg})$ solid solution is $5.7 \mathrm{wt} \%$ at $803 \mathrm{~K}^{[11]}$, and thermally stable Sm-rich intermetallic compounds had been found in the magnesium alloy $^{[12]}$. Furthermore, these stable intermetallic compounds would improve mechanical properties of magnesium alloys $^{[13,14]}$. However, microstructure and mechanical properties of AZ61 magnesium alloys with Sm addition have not been extensively examined or identified clearly. The present study focuses on these properties of AZ61 magnesium alloys with the addition of Sm.

Received date: September 20, 2015

Foundation item: National Natural Science Foundation of China $(51165032,51405216)$

Corresponding author: Hu Zhi, Ph. D., Associate Professor, School of Mechanical and Electrical Engineering, Nanchang University, Nanchang 330031, P. R. China, Tel: 0086-791-83969633, E-mail: huzhi215@163.com

Copyright $($ C 2016, Northwest Institute for Nonferrous Metal Research. Published by Elsevier BV. All rights reserved. 


\section{Experiment}

Five alloys with the basic composition of AZ61 magnesium alloy at $1023 \mathrm{~K}$ were melted in a steel crucible inside a resistant furnace for $20 \mathrm{~min}$ in an $\mathrm{SF}_{6}$ and $\mathrm{CO}_{2}$ atmosphere. Four of the melts were added with $0.5 \mathrm{wt} \%, 1.0 \mathrm{wt} \%, 1.5 \mathrm{wt} \%$, and $2.0 \mathrm{wt} \% \mathrm{Sm}$ (in the form of $\mathrm{Mg}-15 \mathrm{wt} \% \mathrm{Sm}$ master alloy), and these melts were poured into the metallic molds at $973 \mathrm{~K}$. Chemical composition of as-cast AZ61-XSm magnesium alloys are shown in Table 1. Then AZ61-XSm alloys were heated for solution treatment at $693 \mathrm{~K}$ for $24 \mathrm{~h}$ before quenched in hot water. Then, the specimens were aged at 473 $\mathrm{K}$ for $45 \mathrm{~h}$. The microstructural evolution, the morphological changes in the compounds and the effect of Sm addition were examined. The microstructure of specimens was observed by optical microscopy (OM, Nican M300). An etchant of 4\% nitric acid in alcohol solution was used to reveal the microstructure of the polished specimens. Precipitated phases in AZ61-XSm magnesium alloys were characterized by X-ray diffraction (XRD, Bruker D-8) and scanning electron microscopy (SEM, Quanta 200) with energy dispersive spectroscopy (EDS). Hardness values of samples after aging were measured by HXS-1000AK Vickers hardness tester. Seven microhardness measurements were performed on each specimen, and the average of seven values represents the hardness of each specimen. Mechanical property test were performed using an universal materials test machine (CSS-44200) at room temperature. All tests were performed with an initial strain rate of $2 \mathrm{~mm} / \mathrm{min}$.

\section{Results and Discussion}

\subsection{SEM and XRD analysis of AZ61 magnesium alloy with $\mathrm{Sm}$ addition}

SEM image and EDS spectra of AZ61-1.0Sm magnesium alloy are displayed in Fig.1. Discontinuous gray phases (marked A) and white particles (marked B) distribute uniformly in the $\mathrm{Mg}$ alloy, as shown in Fig.1a. In the EDS spectra (Fig.1b and 1c), discontinuous gray phases are identified as the $\beta-\mathrm{Mg}_{17} \mathrm{Al}_{12}$ phase, and white particles with the size of $1 \sim 7$ $\mu \mathrm{m}$ in the $\alpha(\mathrm{Mg})$ grains are a kind of Sm-rich intermetallic compound. The heat of mixing of Al-Sm, Mg-Sm and $\mathrm{Zn}-\mathrm{Sm}$ are $-38,-6$ and $8 \mathrm{~kJ} / \mathrm{mole}$, respectively ${ }^{[15-17]}$. Results show that the Al-Sm phase forms more easily than the other phases. Hence, these white particles may be a mixture of $\mathrm{Mg}_{17} \mathrm{Al}_{12}$ and Sm-rich intermetallic compound. The EDS element line scanning of Sm-rich intermetallic compounds are shown in Fig.2. It can be seen that the main components of the Sm-rich intermetallic compound center region is $\mathrm{Al}$ and $\mathrm{Sm}$ elements, and only the $\mathrm{Mg}$ element distributes around the Sm-rich intermetallic compound. The results demonstrate that the $\mathrm{Al}-\mathrm{Sm}$ intermetallic compounds form first in the as-cast AZ61-1.0Sm alloy. Son et $\mathrm{al}^{[17]}$ found that these Al-Sm-rich intermetallic compounds in $\mathrm{Mg}$-Al-Ca alloys were mainly composed of $\mathrm{Al}$ and $\mathrm{Sm}$ elements with an atomic ratio of $\mathrm{Al}$ : $\mathrm{Sm}=2.36: 1$, and the Sm-rich intermetallic compound is markedly closer to the stoichiometric composition of $\mathrm{Al}_{2} \mathrm{Sm}$.

In order to further research the main component of Sm-rich intermetallic compounds, AZ61 and AZ61-1.0Sm magnesium alloys were analyzed by XRD. As shown in Fig.3, the XRD pattern reveals that the main phase in the AZ61 magnesium alloy is $\alpha(\mathrm{Mg})$ and $\beta$ - $\mathrm{Mg}_{17} \mathrm{Al}_{12}$ phase. Since Sm element is added into the AZ61 magnesium alloy, the diffraction peaks of $\mathrm{Al}_{2} \mathrm{Sm}$ phase are found. Therefore, the Sm-rich intermetallic compounds in AZ61 magnesium alloys are $\mathrm{Al}_{2} \mathrm{Sm}$ phase according to the XRD and EDS analyses.

\subsection{Microstructure of AZ61 magnesium alloy with Sm addition}

According to the experience law of Tim Rosselli, as the relative value of atomic radius subtraction is greater than $15 \%$, the solid solubility of different atom is much lower. For the relative value of atomic radius subtraction of $\mathrm{Sm}-\mathrm{Mg}$ is $44.8 \%$,

Table 1 Chemical composition of AZ61-XSm magnesium alloys (wt\%)

\begin{tabular}{ccccc}
\hline Alloy & $\mathrm{Al}$ & $\mathrm{Zn}$ & $\mathrm{Sm}$ & $\mathrm{Mg}$ \\
\hline AZ61 & 5.78 & 0.91 & - & Bal. \\
AZ61-0.5Sm & 5.67 & 0.84 & 0.56 & Bal. \\
AZ61-1.0Sm & 5.82 & 0.88 & 0.96 & Bal. \\
AZ61-1.5Sm & 5.74 & 0.84 & 1.58 & Bal. \\
AZ61-2.0Sm & 5.76 & 0.94 & 1.89 & Bal. \\
\hline
\end{tabular}
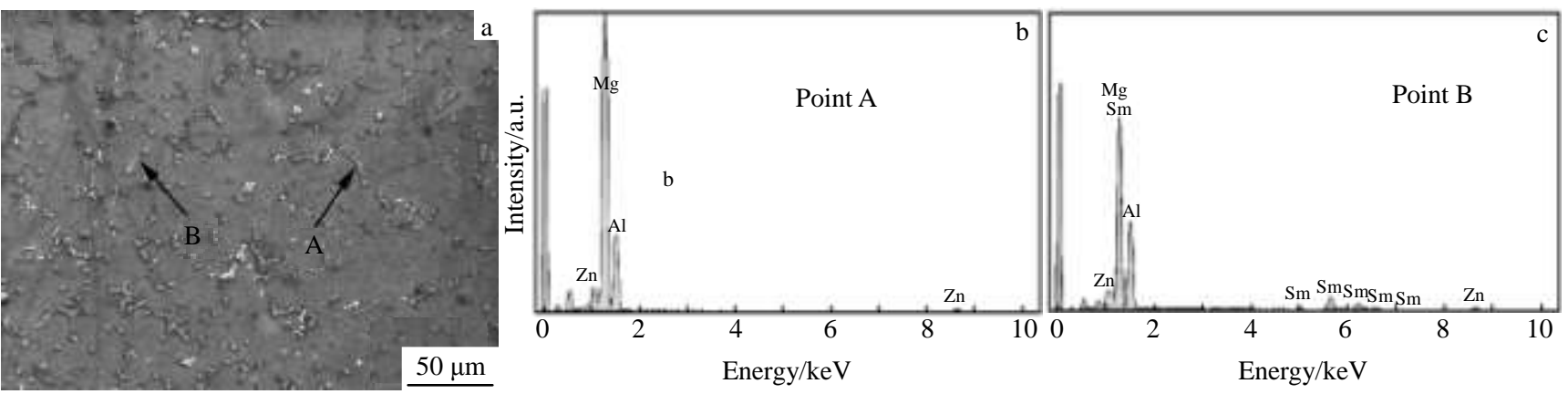

Fig.1 SEM image (a) and EDS spectra of as-cast AZ61-1.0Sm: (b) point A in Fig.1a; (c) point B in Fig.1a 

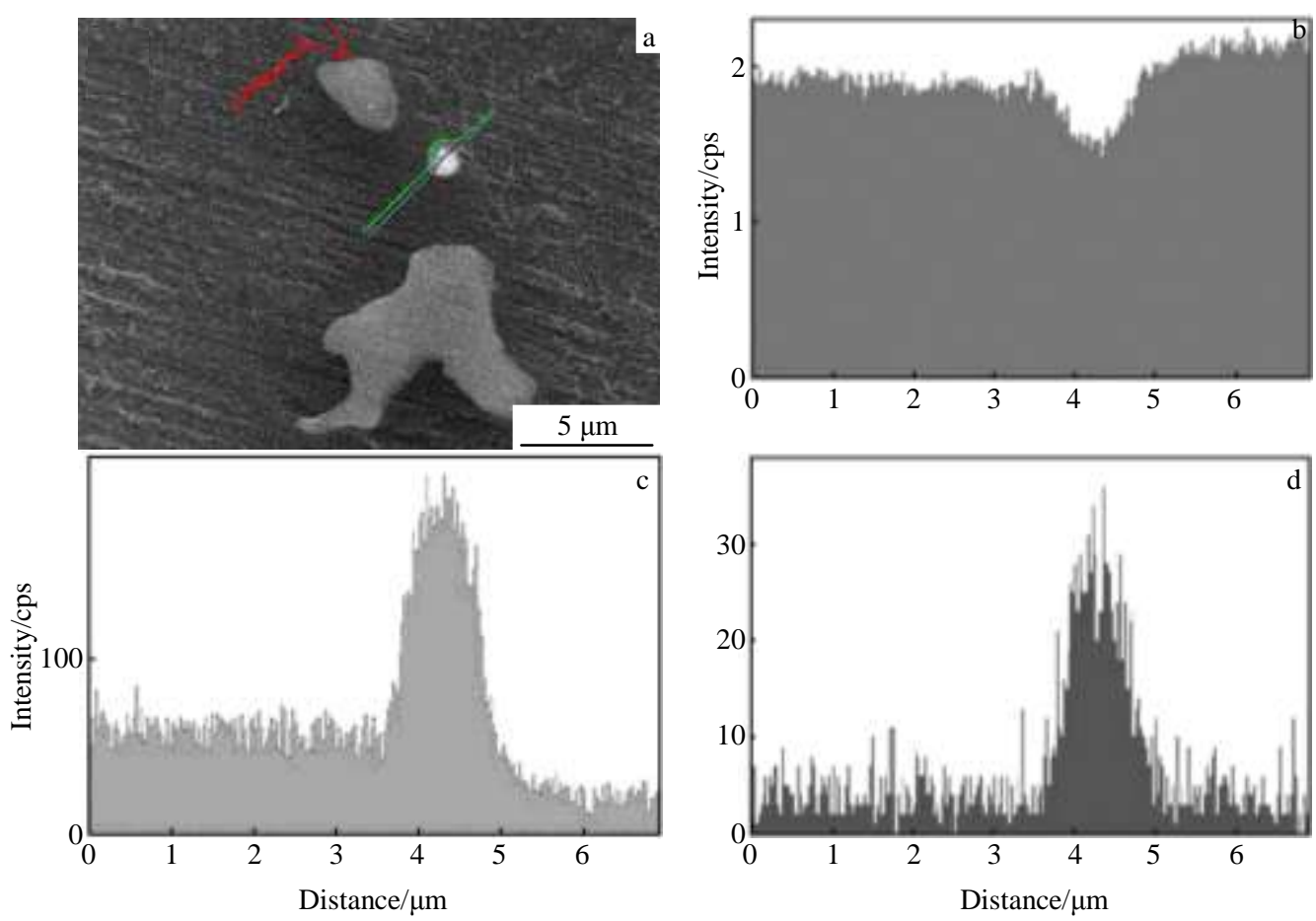

Fig.2 SEM image (a) and corresponding region EDS element line scanning of the Sm-rich intermetallic compound: (b) Mg; (c) Al; (d) Sm
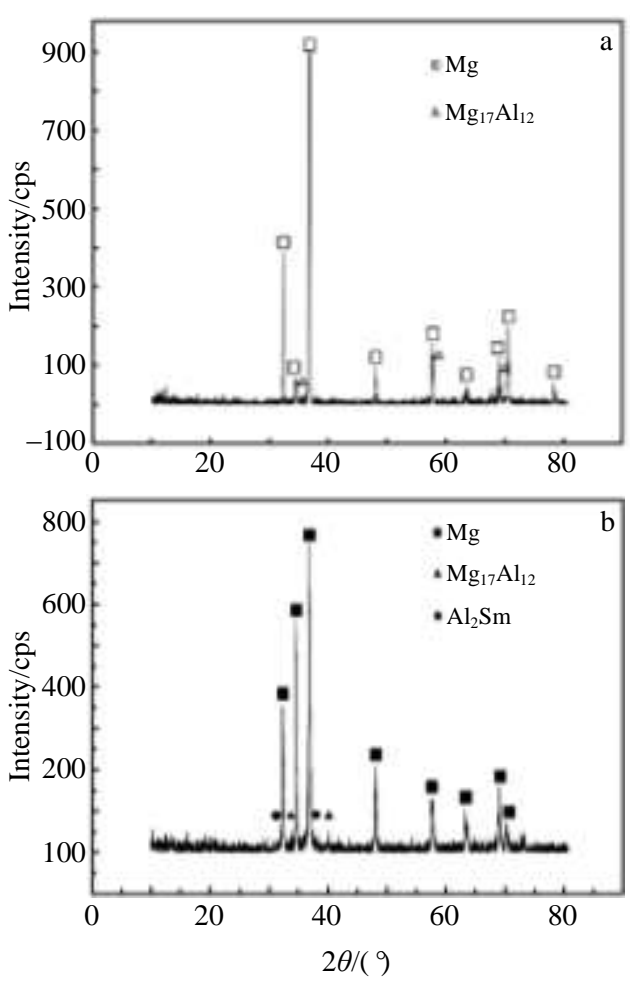

Fig.3 XRD patterns of the AZ61-XSm alloys: (a) $0.0 \mathrm{wt} \% \mathrm{Sm}$ and (b) $1.0 \mathrm{wt} \% \mathrm{Sm}$

the Sm atoms have low solubility in $\mathrm{Mg}$ atoms and the majority of Sm atoms would exist in intermetallic compounds form $^{[18,19]}$. However, the existence form of Sm-rich inter- metallic compounds is affected by Sm content. In order to investigate the effect of Sm addition content on Sm-rich intermetallic compounds, AZ61-XSm magnesium alloy specimens were observed by optical microscopy, and the results are shown in Fig.4. As mentioned above, the particle of intermetallic compound is $\mathrm{Al}_{2} \mathrm{Sm}$ phase. These $\mathrm{Al}_{2} \mathrm{Sm}$ particles are only found in the AZ61 magnesium alloy with Sm addition, as the arrows indicated in Fig.4b and 4c. And the size of these particles in alloys gradually increases with the Sm content increasing (Fig.4d and 4e). Meanwhile, some particles tend to gather and form to a coarse aggregate area. The volume fraction of $\mathrm{Al}_{2} \mathrm{Sm}$ particles in AZ61-XSm magnesium alloys was measured by the Image-Pro Plus, and the results are shown in Table 2. It can be clearly seen that the volume fraction and average diameter of $\mathrm{Al}_{2} \mathrm{Sm}$ particles both increase with $\mathrm{Sm}$ content increasing. When Sm content is $2.0 \mathrm{wt} \%$ added to AZ61 magnesium alloy, the volume fraction and average diameter of $\mathrm{Al}_{2} \mathrm{Sm}$ particles reach to $2.2 \%$ and $6.8 \mu \mathrm{m}$, respectively.

Optical microstructures of as-cast AZ61 magnesium alloy with different Sm additions are illustrated in Fig.5. Microstructure of the AZ61 magnesium alloy mainly consists of primary $\alpha(\mathrm{Mg})$ grains with $\beta$ - $\mathrm{Mg}_{17} \mathrm{Al}_{12}$ phases at the surrounding boundaries (Fig.5a). In the Sm modified alloys, discontinuous phases and particle phases were proved by SEM and XRD to be the $\beta-\mathrm{Mg}_{17} \mathrm{Al}_{12}$ phase and the $\mathrm{Al}_{2} \mathrm{Sm}$ intermetallic compound. It can be seen that the size and the content of $\beta$ - $\mathrm{Mg}_{17} \mathrm{Al}_{12}$ phases decrease in the as-cast microstructure with the increasing of Sm content, as shown in Fig.5. The volume fraction of $\beta-\mathrm{Mg}_{17} \mathrm{Al}_{12}$ phases also shows the similar results, 

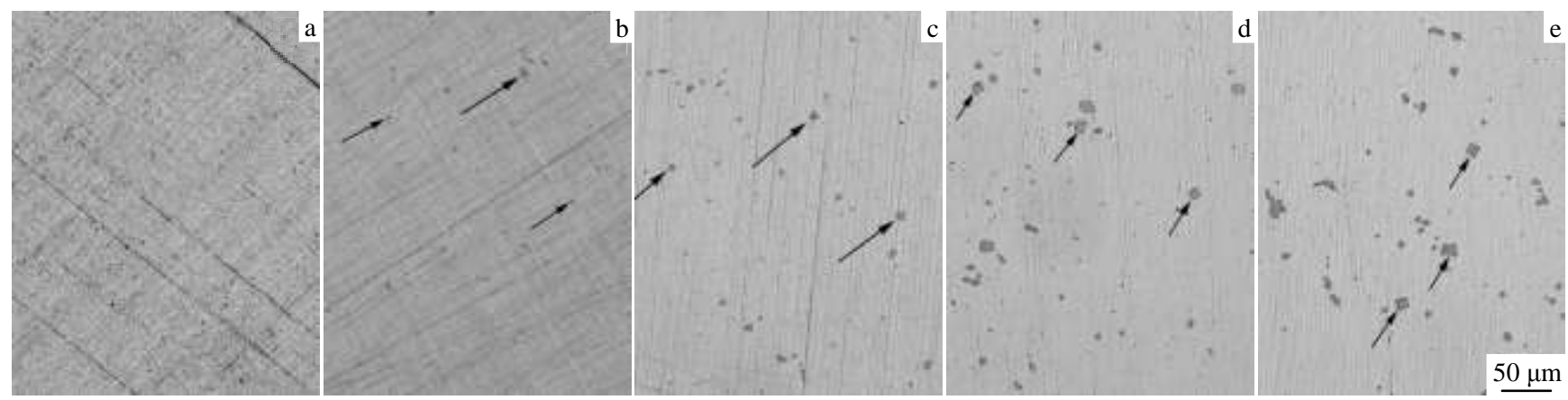

Fig.4 Effect of Sm addition content on Sm-rich intermetallic compounds: (a) AZ61, (b) AZ61-0.5Sm, (c) AZ61-1.0Sm,

(d) AZ61-1.5Sm, and (e) AZ61-2.0Sm

as shown in Table 2. The volume fraction of $\beta-\mathrm{Mg}_{17} \mathrm{Al}_{12}$ phases decreases from $10.8 \%$ to $5.6 \%$ as Sm content increases from $0.0 \mathrm{wt} \%$ to $2.0 \mathrm{wt} \%$. However, when the $\mathrm{Sm}$ content exceeds to $1.0 \mathrm{wt} \%, \beta-\mathrm{Mg}_{17} \mathrm{Al}_{12}$ phases connect with coarse $\mathrm{Al}_{2} \mathrm{Sm}$ phases and tend to aggregate as shown in Fig.5d and 5e, which would be harmful to mechanical properties of the AZ61 magnesium alloy.

The Al-Sm and Mg-Al binary phase diagrams show that the $\mathrm{Al}_{2} \mathrm{Sm}$ phase forming temperature is higher than that of $\mathrm{L} \rightarrow \alpha(\mathrm{Mg})+\beta-\mathrm{Mg}_{17} \mathrm{Al}_{12}$. Hence, the $\mathrm{Al}_{2} \mathrm{Sm}$ phase first forms and accumulates at the front edge of the liquid solid interface during alloy solidification, causing compositional undercooling and refining the $\beta-\mathrm{Mg}_{17} \mathrm{Al}_{12}$ phase. Meanwhile, the form of $\mathrm{Al}_{2} \mathrm{Sm}$ phase also largely consumes the $\mathrm{Al}$ atoms in AZ61 melts during solidification, which inhibit the form

Table 2 Volume fraction and average diameter of $\mathrm{Al}_{2} \mathrm{Sm}$ and $\beta$ - $\mathrm{Mg}_{17} \mathrm{Al}_{12}$

\begin{tabular}{|c|c|c|c|}
\hline Alloy & $\begin{array}{c}\text { Volume fraction } \\
\text { of } \mathrm{Al}_{2} \mathrm{Sm} / \% \\
\end{array}$ & 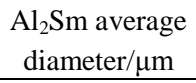 & $\begin{array}{c}\text { Volume fraction of } \\
\quad \beta-\mathrm{Mg}_{17} \mathrm{Al}_{12} / \% \\
\end{array}$ \\
\hline AZ61 & - & - & 10.8 \\
\hline AZ61-0.5Sm & 0.4 & 1.6 & 9.5 \\
\hline AZ61-1.0Sm & 0.8 & 3.3 & 7.0 \\
\hline AZ61-1.5Sm & 1.7 & 5.6 & 6.3 \\
\hline AZ61-2.0Sm & 2.2 & 6.8 & 5.6 \\
\hline
\end{tabular}

and growth of $\beta-\mathrm{Mg}_{17} \mathrm{Al}_{12}$ phase.

The microhardness of as-cast AZ61 magnesium alloys with different contents of $\mathrm{Sm}$ is shown in Fig.6. The microhardness of AZ61 magnesium alloys increases with the increasing of addition of Sm and reaches to the highest value of $612 \mathrm{MPa}$ when $\mathrm{Sm}$ content is $2.0 \mathrm{wt} \%$. The increase of microhardness is mainly attributed to the volume fraction of $\mathrm{Al}_{2} \mathrm{Sm}$ particles increasing.

Optical microstructures of AZ61-XSm magnesium alloys after solution treatment are shown in Fig.7. It can be seen that the grain size decreases with the increasing of additions of Sm and achieves to the lowest value when Sm content is $1.0 \mathrm{wt} \%$. Similar results were reported by H. T. Son et al ${ }^{[20]}$, and they believed that the calculation of the planar disregistry is $12.29 \%$ when the orientation relationship between $\mathrm{Al}_{2} \mathrm{Sm}$ phase and $\alpha(\mathrm{Mg})$ phase is $(111)_{\mathrm{Al}_{2} \mathrm{Sm}} / /\left(10 \overline{1} 0_{\alpha-\mathrm{Mg}}\right)$, which is less than $15 \%$. Therefore, the $\mathrm{Al}_{2} \mathrm{Sm}$ particles could cause heterogeneous nucleation in the $\alpha(\mathrm{Mg})$ phase. When the Sm content exceeds $1.0 \mathrm{wt} \%$, the effects of heterogeneous nucleation caused by $\mathrm{Al}_{2} \mathrm{Sm}$ particles decrease because of $\mathrm{Al}_{2} \mathrm{Sm}$ particles growth and agglomeration.

Fig. 8 shows the effect of ageing time on microhardness of AZ61-XSm magnesium alloy aged at $473 \mathrm{~K}$. It can be seen from the aging-hardening curves that AZ61-XSm magnesium

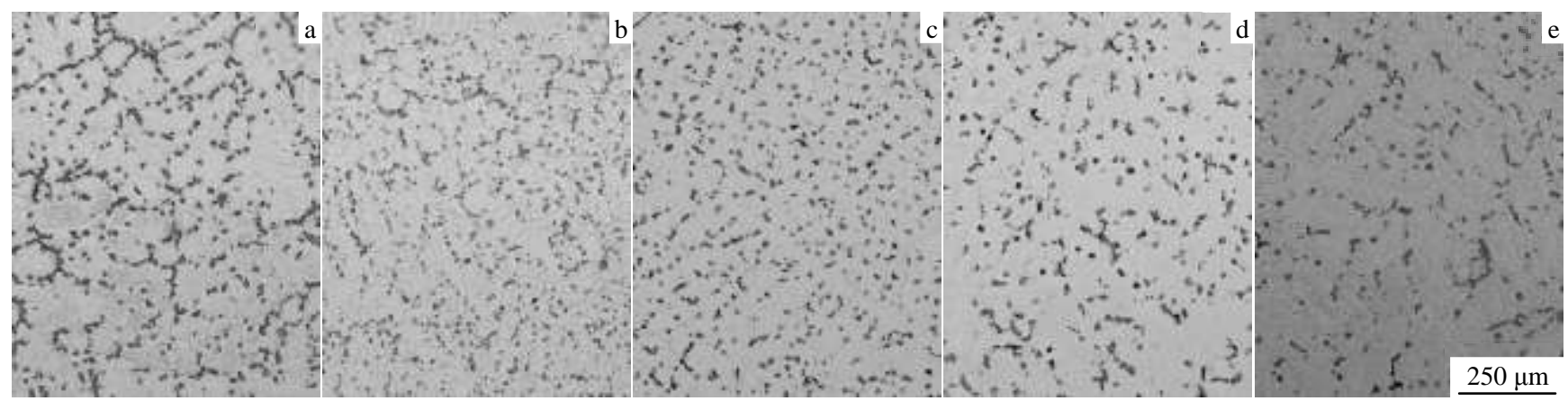

Fig.5 Optical microstructures of as-cast AZ61-XSm magnesium alloy: (a) AZ61, (b) AZ61-0.5Sm, (c) AZ61-1.0Sm, (d) AZ61-1.5Sm, and (e) AZ61-2.0Sm 


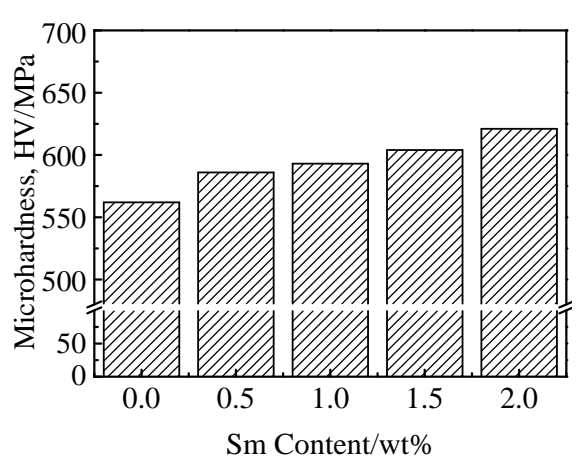

Fig.6 Microhardness of as-cast AZ61-XSm magnesium alloys

alloys have similar aging characteristics; both of them experience the under aging, peak aging and over aging periods. The peak aging time for the AZ61-1.0Sm alloy and the AZ61-2.0Sm alloy are $20 \mathrm{~h}$ while for the AZ61 matrix alloy is $25 \mathrm{~h}$, which reveals that the aging process of modified alloys is shorter than that of the unmodified alloy at $473 \mathrm{~K}$. The possible reason is mainly attributable to a lot of dislocations formed in the modified alloy during the solid solution and aging treatment process. These dislocations derive from the different thermal expansion coefficients between the $\mathrm{Al}_{2} \mathrm{Sm}$ particle and the $\mathrm{AZ61}$ magnesium alloy, and supply more channels for solute diffusion, which accelerates the diffusion of solute ${ }^{[21]}$.

\subsection{Mechanical properties of AZ61-XSm magnesium alloys after solution treatment}

Fig.9 shows the effect of Sm addition on mechanical properties of AZ61-XSm magnesium alloys after solution treatment at room temperature. The ultimate tensile strength and yield stress of the AZ61-XSm magnesium alloys increase with the increasing of $\mathrm{Sm}$ additions and achieve the highest value when the $\mathrm{Sm}$ content is $1.0 \mathrm{wt} \%$, which are about 215 and $142 \mathrm{MPa}$, respectively. However, further increasing Sm content would degrade the tensile strength and yield stress of AZ61 magnesium alloys. The maximum elongation of AZ61 magnesium alloys is also obtained from $1.0 \mathrm{wt} \%$ Sm modified alloy with fine $\alpha(\mathrm{Mg})$ grain. And the elongation is approximately $4.1 \%$. It indicates that $\mathrm{Sm}$ can obviously improve mechanical properties of the AZ61 magnesium alloy after solution treatment.

The mechanism for strengthening AZ61-XSm magnesium alloys may be attributed to the following factors: 1) dispersion strengthening: according to the enthalpies of formation for Al-Sm system $(-38 \mathrm{~kJ} / \mathrm{mole})$ smaller than those of $\mathrm{Mg}-\mathrm{Al}$, $\mathrm{Mg}-\mathrm{Sm}$ and $\mathrm{Zn}-\mathrm{Sm}$ system $\left(-15,-6,8 \mathrm{~kJ} / \mathrm{mole}\right.$, respectively ${ }^{[22]}$, $\mathrm{Sm}$ atoms will firstly react with $\mathrm{Al}$ atom and form $\mathrm{Al}_{2} \mathrm{Sm}$ phase, which has been proved by the above mentioned results. The discontinuous $\beta$ - $\mathrm{Mg}_{17} \mathrm{Al}_{12}$ phase presented in modified alloys shows that $\mathrm{Sm}$ atoms in alloys have fully reacted. Furthermore, the components of AZ61-XSm magnesium alloys are $\alpha(\mathrm{Mg})$, $\beta-\mathrm{Mg}_{17} \mathrm{Al}_{12}$ and $\mathrm{Al}_{2} \mathrm{Sm}$, and thus the dispersion particles can only be confirmed as $\mathrm{Al}_{2} \mathrm{Sm}$ phase. These particles with the size of $1 \sim 7 \mu \mathrm{m}$ in the AZ61-XSm magnesium alloys can effectively hinder the movement of dislocations and strengthen grain boundary through Orowan strengthening. 2) solution strengthening: the atomic radius of $\operatorname{Sm}\left(R_{\mathrm{Sm}}=0.259\right)$ is larger than that of $\mathrm{Al}$ and $\mathrm{Mg}\left(R_{\mathrm{Al}}=0.143\right.$ and $\left.R_{\mathrm{Mg}}=0.160\right)$. Thus, Sm solubilizes in $\mathrm{Mg}$ and the substitutional solid solution is formed. The Sm atom in the $\mathrm{Mg}$ alloys would cause lattice distortion, which increases the dislocation motion resistance, and then remarkably impedes slip and improves the strength of the AZ61 magnesium alloy. The solid solubility of $\mathrm{Sm}$ in $\mathrm{Mg}$ is $0.063 \%$ (atom fraction) at room temperature reported by $\mathrm{Li}$ et al ${ }^{[23]}$, and they found that the strengthening increment $\Delta \sigma_{\mathrm{s}}$ caused by Sm solubilizing in $\mathrm{Mg}$ is 29.8 MPa. 3) grain-refinement strengthening: the smaller the grain size of the AZ61-XSm alloy, the larger the deformation resistance caused by a lot of grain boundaries, and therefore the mechanical strength is improved ${ }^{[24]}$.

However, too much Sm content in AZ61 magnesium alloy would form coarse $\mathrm{Al}_{2} \mathrm{Sm}$ intermetallic compound, which easily cause stress concentration. Cracks can be easily generated during the loading process and propagate preferentially along the interface of coarse $\mathrm{Al}_{2} \mathrm{Sm}$ phase and matrix, then affecting mechanical properties of the AZ61 magnesium alloy ${ }^{[25]}$.

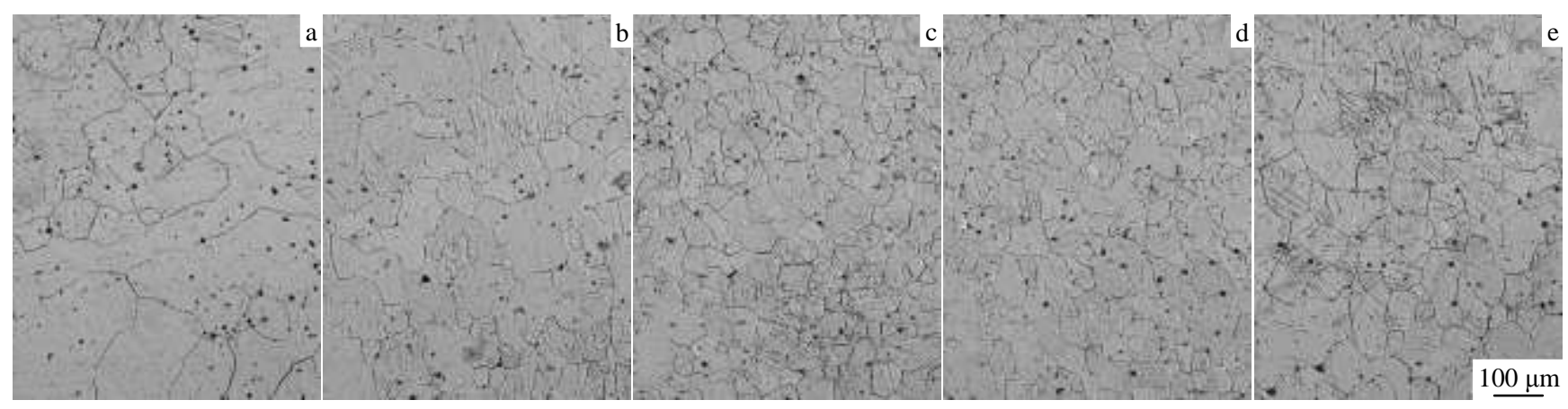

Fig.7 Optical microstructures of AZ61-XSm magnesium alloys after heat treatment: (a) AZ61; (b) AZ61-0.5Sm; (c) AZ61-1.0Sm; (d) AZ61-1.5Sm; (e) AZ61-2.0Sm 


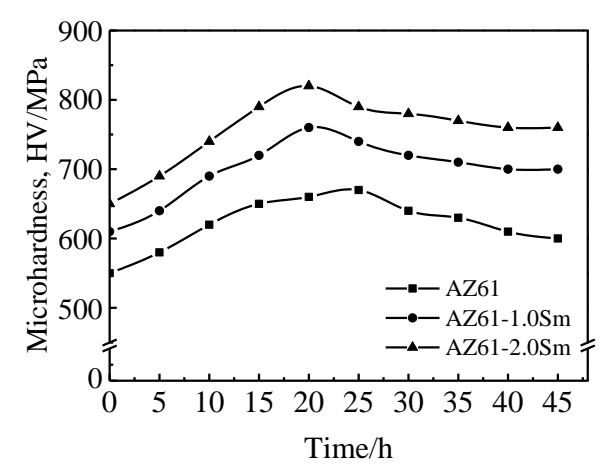

Fig.8 Effect of ageing time on microhardness of AZ61-XSm magnesium alloys aged at $473 \mathrm{~K}$

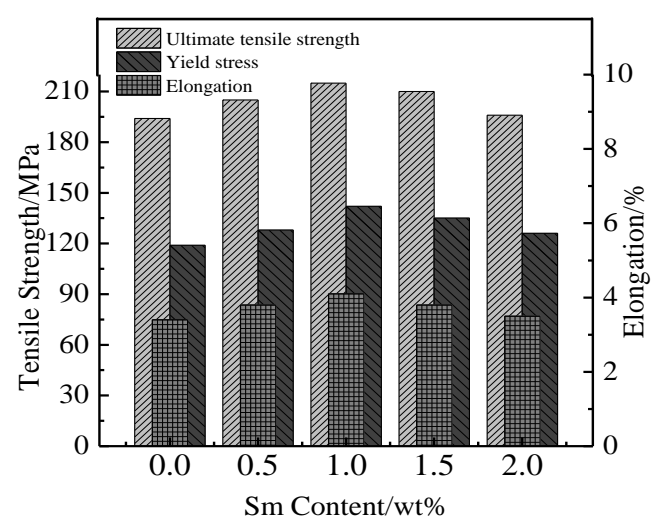

Fig.9 Mechanical properties of AZ61-XSm magnesium alloys after solution treatment at room temperature

\section{Conclusions}

1) $\mathrm{The} \mathrm{Al}_{2} \mathrm{Sm}$ particles of intermetallic compound with the size of $1 \sim 7 \mu \mathrm{m}$ are found in AZ61 magnesium alloy with different $\mathrm{Sm}$ content additions. The size of $\mathrm{Al}_{2} \mathrm{Sm}$ particles in alloys gradually increases with the Sm content increasing, and some of particles tend to agglomerate when Sm content exceeds $1.0 \mathrm{wt} \%$.

2) The grain size and the volume fraction of $\beta-\mathrm{Mg}_{17} \mathrm{Al}_{12}$ phase of AZ61-XSm magnesium alloys decrease with the increasing of $\mathrm{Sm}$ content, and the grain size achieves the lowest value when the $\mathrm{Sm}$ content is $1.0 \mathrm{wt} \%$.

3) When the Sm content is $1.0 \mathrm{wt} \%$, the ultimate tensile strength and yield stress of AZ61 magnesium alloys after solution treatment reaches their maximum values, 215 and 142 $\mathrm{MPa}$, respectively. The maximum elongation is approximately $4.1 \%$.

\section{References}

1 Hai Z Y, Xing Y L. J Mater Sci[J], 2004, 39: 6153

2 Sevik H, Açıkgöz S, Kurnaz S C. J Alloy Compd[J], 2010, 508: 110

3 Lan J, Yang Y, Li X C. Mater Sci Eng A[J], 2004, 386: 284

4 Hantzsche K, Bohlen J, Wendt J et al. J Scr Mater[J], 2010, 63: 725

5 Pan F S, Chen M B, Wang J F et al. Tran Nonferr Metal Soc[J], 2008, 18(S1): 1

6 Wang M X, Zhou H, Wang L. J Rare Eart[J], 2007, 25: 233

7 Bai P C, Dong T S, Hou X H et al. Mater Char[J], 2010, 61: 756

8 Zhang J W, Wang S B, Zhang J Y et al. Rare Met Mat Eng $[\mathrm{J}]$, 2009, 38(7): 1141

9 Liu W J, Cao F H, Chang L R et al. Corros Sci[J], 2009, 51: 1334

10 Huang W X, Yan H. Proc IEEE Int Conf[C]. Harbin: IEEE Computer Society, 2011: 2609

11 Okamoto H. J Ph Equil Diff]J], 2009, 30: 299

12 Li K J, Li Q A, Jing X T et al. Rare Metals[J], 2009, 28: 516

13 Zheng J, Wang Q D, Jin Z L et al. Mat Sci Eng A[J], 2010, 527: 1677

14 Zhang Q. Li Q A, Jing X T. J Rare Eart[J], 2010, 28: 375

15 Zhou S H, Napolitano R E. Met Mat Tran A[J], 2008, 39: 502

16 Wang C P, Zhang H L, Wang S L et al. J Alloy Compd[J], 2009, 481: 291

17 Son H T, Lee J S, Kim D G et al. J Alloy Compd[J], 2009, 473: 446

18 Son H T, Lee J S, Kim D G et al. Adv Mater Res[J], 2007, 24-25: 153

19 Chen Z H. Heat Resistant Magnesium Alloys[M]. Beijing: Chemical Industry Press, 2006: 60

20 Son H T, Lee J S, Kim D G et al. Key Eng Mat[J], 2007, 345-346: 653

21 Yan H, Hu X W, Nie Q et al. China Foundry[J], 2011, 8: 269

22 Huang W X, Yan H. J Wuhan Univ Technol Mater Sci Ed[J], 2014, 29: 374

23 Li K J, Li Q A. Chinese Rare Earths[J], 2012, 33: 28

24 Li K J, Li Q A, Jing X T et al. Scripta Mater[J], 2009, 60:1101

25 Yuan G Y, Liu M P, Wang Q D et al. Acta Metall Sin[J], 2002, 38: 1105 


\title{
稀土元素 Sm 对 AZ61 镁合金的组织与力学性能的影响
}

胡 ${ }^{1}{ }^{1,2}$, 华 群 $^{1}$, 用 洪 $^{1}$, 揭小平 ${ }^{1}$, 饶远生 ${ }^{1}$

(1. 南昌大学, 江西 南昌 330031)

(2. 南昌市轻合金制备和加工重点实验室, 江西 南昌 330029)

\begin{abstract}
摘 要: 采用 OM, XRD, SEM 和 EDS 等分析手段, 研究了不同含量的稀土元素钐(质量分数, $0.0 \%, 0.5 \%, 1.0 \%, 1.5 \%$ 和 $2.0 \%$ )对 $\mathrm{AZ61}$ 镁合金组织与性能的影响。结果表明: 在含钐为 $0.5 \%$ 2.0\%的 AZ61 镁合金中发现了大量的颗粒状 $\mathrm{Al}_{2} \mathrm{Sm}$ 金属间化合物（体积分

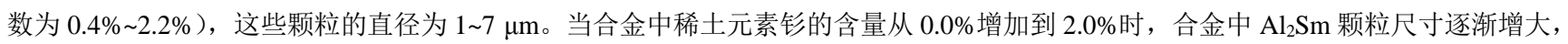
而 $\beta-\mathrm{Mg}_{17} \mathrm{Al}_{12}$ 的含量却不断减小。经 $693 \mathrm{~K}$ 固溶 $24 \mathrm{~h}$ 的含钐 $\mathrm{AZ61}$ 镁合金的晶粒尺寸随着钐含量的增加而先减小后增加, 当钐含量为 $1.0 \%$ 时, 合金的晶粒尺寸最小。固溶态 AZ61 镁合金中的钐含量达到 $1.0 \%$ 时, 合金的极限抗拉强度、屈服强度和延伸率都达到最大, 分别为 $215 、 142 \mathrm{MPa}$ 和 $4.1 \%$ 。
\end{abstract}

关键词：稀土; 钐; 镁合金; 金属间化合物; 微观组织; 力学性能

作者简介: 胡 志, 男, 1983 年生, 博士, 副教授, 南昌大学机电工程学院, 江西 南昌 330031, 电话: 0791-83969633, E-mail: huzhi215@163.com 